\title{
Once daily nebulized beclomethasone is effective in maintaining pulmonary function and improving symptoms in asthmatic children
}

\author{
S. La Grutta1, G. Nicolini2, C. Capristo3, S.C. Bellodi4, G.A. Rossi4
}

ABSTRACT: Once daily nebulized beclomethasone is effective in maintaining pulmonary function and improving symptoms in asthmatic children. S. La Grutta, G. Nicolini, C. Capristo, S.C. Bellodi, G.A. Rossi.

Background and Aim. Compliance with long-term inhaled therapy in asthma is often poor, but it is likely to be improved with a simplified administration, once daily.The present study was designed to assess whether, in childhood asthma, a single dose of nebulized beclomethasone dipropionate once daily was as effective and safe as the same total daily dose administered twice daily.

Methods. Asthmatic children, not treated with inhaled steroids for at least a month preceding the study and using short-acting bronchodilators more than once a week were enrolled in a double-blind, double dummy, randomised, multicentric study. After a two week run-in period on nebulised twice daily $\mathbf{4 0 0} \mathrm{mcg}$ beclomethasone dipropionate, patients were randomly assigned to twelve weeks of treatment with $800 \mathrm{mcg}$ nebulised beclomethasone dipropionate daily, either in single dose (o.d. group) or divided into two 400 mcg doses (b.i.d. group).

Results. 65 children (mean age 8.6 years, mean FEV $_{1}$ $81 \%$ of predicted), were valuable for intention to treat.
During the run-in period, a significant improvement in $\mathrm{FEV}_{1}, \mathrm{FVC}$, morning and evening PEF values and clinical scores was observed. Children then entered the randomised trial: 32 were included in the o.d. group and 33 in the b.i.d. group. During the twelve week treatment period, the observed improvement in pulmonary function parameters was maintained in both treatment groups. Morning and evening PEF showed a progressive slight increase as well as PEF diurnal variability showed a progressive reduction in the two treatment groups during the whole study period without reaching statistical significance. Moreover, in both treatment groups a similar progressive increase in symptom free nights and days and in the percentage of children achieving total asthma symptoms control was detected. Finally, no significant changes in urinary cortisol/creatinine ratio were observed throughout the study period and between groups.

Conclusions. A daily dose of $800 \mathrm{mcg}$ of beclomethasone, administered for twelve weeks with a nebuliser either once or twice daily provide similar efficacy in maintaining pulmonary function and symptoms of asthmatic children, with a good tolerability profile.

Monaldi Arch Chest Dis 2007; 67: 1, 30-38.

Keywords: Inhaled corticosteroids, childhood asthma, nebulizers, once daily.

${ }^{1}$ Children Hospital ARNAS, Palermo,

2 Chiesi Farmaceutici S.p.A., Parma,

3 University of Naples,

${ }^{4}$ I.R.C.C.S. Gaslini, Genoa, Italy.

Correspondence: Giovanni A. Rossi; U.O. di Pneumologia, Istituto G. Gaslini, Largo Gaslini 5, 16147 Genova, Italy; e-mail: giovannirossi@ospedale-gaslini.ge.it

\section{Introduction}

Therapeutic strategies used to achieve and maintain asthma control involve several considerations, such as the selection of appropriate medication(s) and route for administration, based not only on disease persistency and severity, but also on patient preference and ability to comply with therapy [1]. Inhaled corticosteroids (ICS) are the most effective and recommended drugs to control asthma in patients of any age and allow the use of very low doses which are delivered directly into the lungs with low systemic exposure $[1,2]$.

However, patient adherence to long-term inhaled therapy is often low, resulting in increased patient morbidity [3, 4]. Patient compliance can be increased with less complex dosing regimens of
ICS in asthma $[1,2,4]$ and a patient preference for once-daily dosing has been demonstrated $[4,5]$, suggesting that this strategy could lead to improved efficacy [6]. This is a key factor in childhood asthma, where the benefits of early intervention with ICS have been recently emphasised and where the most common reason for treatment inefficacy is lack of compliance $[1,2,7]$.

Few controlled clinical trials have been performed in asthmatic children comparing the efficacy of once- versus twice-daily dosing of ICS. However, once-daily administration of budesonide using a dry powder inhaler (DPI) or a nebuliser, seems to be as effective as twice-daily administration in controlling childhood asthma [8-12]. The pharmacologic properties of budesonide [13] probably account for its long-lasting activity [14]. Pre- 
liminary or less convincing results have been published on effective childhood asthma control with once-daily administration of other ICS [8].

Interestingly, there is no paediatric study that has investigated the efficacy of the once-daily administration of beclomethasone dipropionate (BDP), a widely used glucocorticoid diester for the inhalation therapy of asthma. In adult patients with asthma, once daily doses of $1000 \mathrm{mcg}$ BDP given via a pressurised metered-dose inhaler (pMDI) provided contrasting results: either equivalent control to twice-daily doses [15] or bad control of asthma when switching from t.i.d. or b.i.d. to o.d. $[16,17]$.

ICS are available in different formulations to be delivered with different inhaler devices, like pMDIs, DPIs and nebulizers; the choice of the inhalation device is another critical factor for optimal asthma therapy [18]. Recent evidence-based guidelines have indicated that the same molecule given via different devices (including nebulizers) leads to no significant differences in clinical outcomes and the choice depends on the patient preference and ability to use [19-21]. In children older than 6 years the preferred option is represented either by a pMDI with or without spacer (depending on the coordination ability of the subject) or by a DPI, while the nebuliser with mouthpiece is an alternative [19-21].

Nebulisers do not need patient coordination and are effective with tidal breathing, don't use propellants and can deliver combination therapy or supplemental oxygen [21]. Due to the characteristics of new generation nebulizers, more efficient and faster in drug delivering, the use of these devices is becoming more common in clinical practice [20].

With this background, the present study was designed to compare the efficacy of once-daily versus twice-daily administration of nebulized BDP suspension, in asthmatic, school-age children.

\section{Methods}

\section{Patients}

Children aged 5-12 yrs with a history of asthma, as defined by the American Thoracic Society [22], for at least the previous 6 months were recruited from outpatient asthma clinics. Inclusion criteria were: a forced expiratory volume in one second $\left(\mathrm{FEV}_{1}\right)$ values $\geq 70 \%$ and $\leq 90 \%$ of predicted normal; steroid-naive patients or not treated with ICS at least in the previous four weeks; short-acting $\beta_{2}$-agonists use more than once a week for at least the preceding two weeks; positive response to the reversibility test, defined as an increase $>12 \%$ in the $\mathrm{FEV}_{1}$ following salbutamol $(200 \mathrm{mcg})$ delivered with pMDI and a spacer (Volumatic, Allen \& Hanbury's, Uxbridge, UK), at the screening visit.

Patients were excluded from the study if they were hospitalised for asthma treatment within the previous 3 months, received oral, or parenteral steroid therapy within 12 weeks of screening visit.

The study was approved by the ethics committee of the eight institutions participating in the study. Each child gave informed oral assent, and the child's parents or legal guardians gave written informed consent in accordance with the current version of the Declaration of Helsinki.

\section{Study design and study drugs}

Children who were found eligible at the screening visit entered a 2-week run-in period, during which they were treated with BDP suspension (Clenil per Aerosol, Chiesi Farmaceutici S.p.A., Parma, Italy), at a dose of $800 \mathrm{mcg} /$ day (the standard dose used to treat children with mild asthma using nebulisers) administered b.i.d. (400 mcg in the morning and $400 \mathrm{mcg}$ in the evening), through a pneumatic nebuliser with mouthpiece (Clenny aerosol, Medel S.p.A., Parma, Italy) (fig. 1) [23].

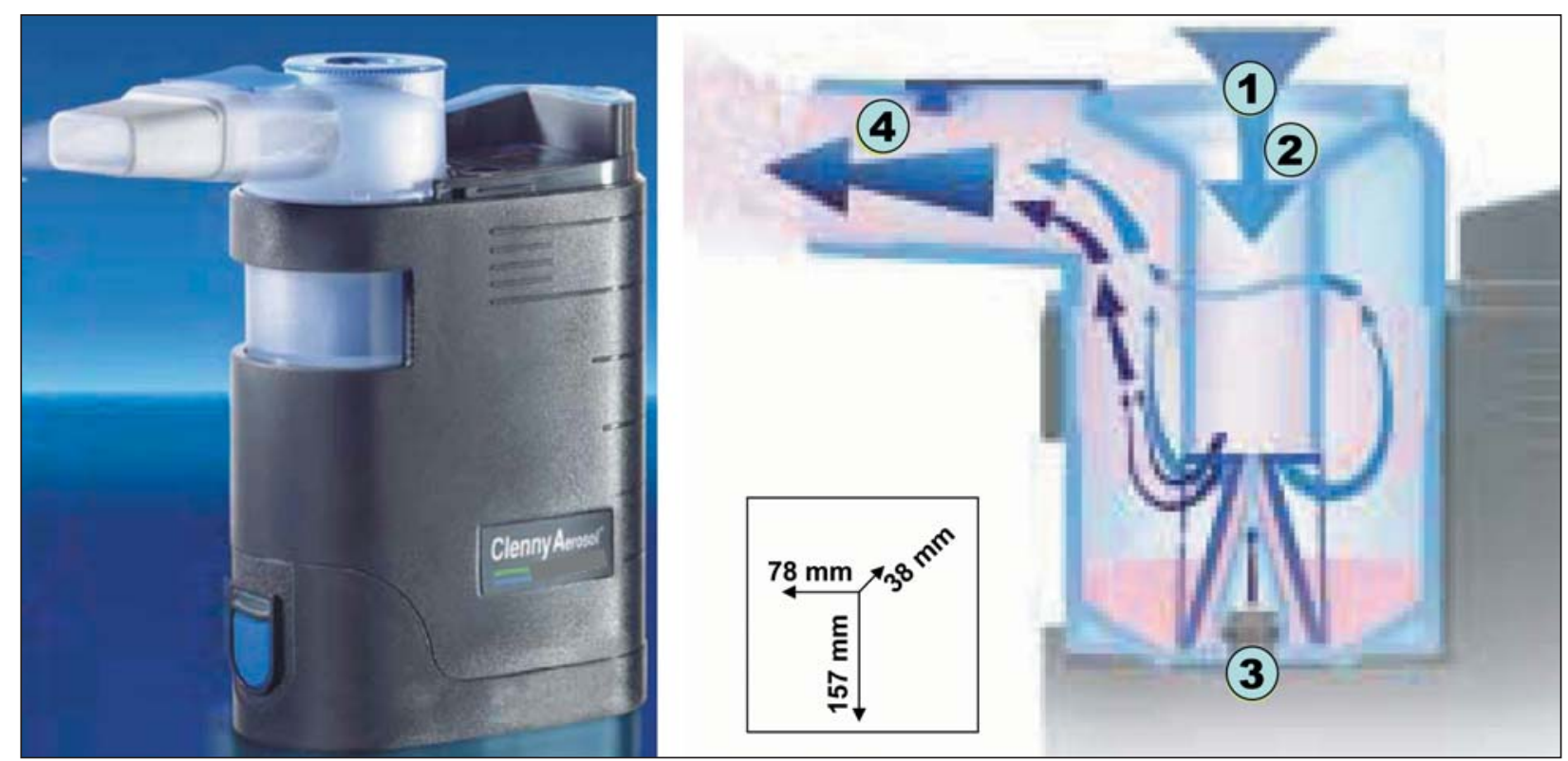

Fig. 1. - The "Clenny nebulizer". A) This is a small (157 mm x $38 \mathrm{~mm}$ x $78 \mathrm{~mm}$, with battery) light (560 g, with battery) breath-enhanced nebuliser, operated by battery and/or A/C power supply. B) The breath enhanced bulb increases the drug output [23]. 
At the end of this period, each patient was reevaluated before entering the 12 weeks, randomised, double-blind, double dummy, two-armed parallel group study period (fig. 2). The following treatments were given during the double-blind period: a) o.d. group: $1 \mathrm{ml}$ placebo vial (containing only the "vehicle" of the BDP vial, to match active treatment) plus $2 \mathrm{ml}$ saline solution, administered in the morning, and $1 \mathrm{ml}$ placebo vial plus $2 \mathrm{ml} \mathrm{BDP}$ $800 \mathrm{mcg}$ vials in the evening; b) b.i.d. group: $1 \mathrm{ml}$ BDP $400 \mathrm{mcg}$ vial plus $2 \mathrm{ml}$ saline solution, in the morning, and $1 \mathrm{ml}$ BDP $400 \mathrm{mcg}$ vial plus $2 \mathrm{ml}$ placebo vial in the evening. Salbutamol $100 \mathrm{mcg}$ pMDI was allowed as rescue medication during all the study period to be administered as needed via a Volumatic spacer. No other asthma medication was allowed. Patients who had poor asthma control, received asthma medication excluded by study protocol or showed exacerbation that required hospitalisation were discontinued from the study.

Children and their parents or legal guardians had to keep a diary card, slightly modified from Banov et al. [24], for recording of Peak Expiratory Flow (PEF) values, asthma symptoms, sleep disturbance scores, study drug intake and inhaled short-acting $\beta_{2}$-agonist use. PEF was to be measured in the morning, immediately upon arising, and in the evening, at bedtime: the best of the three readings was recorded. Patients and their parents or legal guardians were trained in the correct use of the nebuliser, of the PEF meter (Mini Wright, Markos Mefar S.p.A., Bovezzo, Italy) and in data recording before entering the study.

\section{Efficacy evaluation}

Efficacy parameters included variations in pulmonary function parameters, morning and evening PEF and its diurnal variability, day and night asthma symptoms, rescue medication use, overall assessment of asthma symptoms by Visual Analogue Scale (VAS).

Pulmonary function tests were performed using pneumotachograph-type spirometers interfaced with a personal computer system and calibrated to American Thoracic Society standards [25]. Spirometry was performed between 8:30 AM and 10:00 AM at approximately the same time each visit and at least 8 hours after the last use of a short-acting $\beta_{2}$-agoinist and each measurement was performed in triplicate, and the highest value for each test recorded.

Exacerbations were evaluated as secondary efficacy parameter and defined as two consecutive days in which at least one the following occurred: 1) decrease of the peak expiratory flow in the morning more than $30 \%$ below the baseline value; 2 ) use of more than three additional inhalations of short-acting $\beta_{2}$-agonist daily, as compared to baseline period; 3) awakening at night due to asthma. The baseline value was the mean value of the last 10 days of the run-in period.

The evaluation of treatment effectiveness was done by investigators at visit 2, 3, 4, and 5, based on the presence and severity of wheeze and cough (day and night), patient's evaluation of sleep and activity and use of short-acting $\beta_{2}$-agonists since

\section{Study design.}
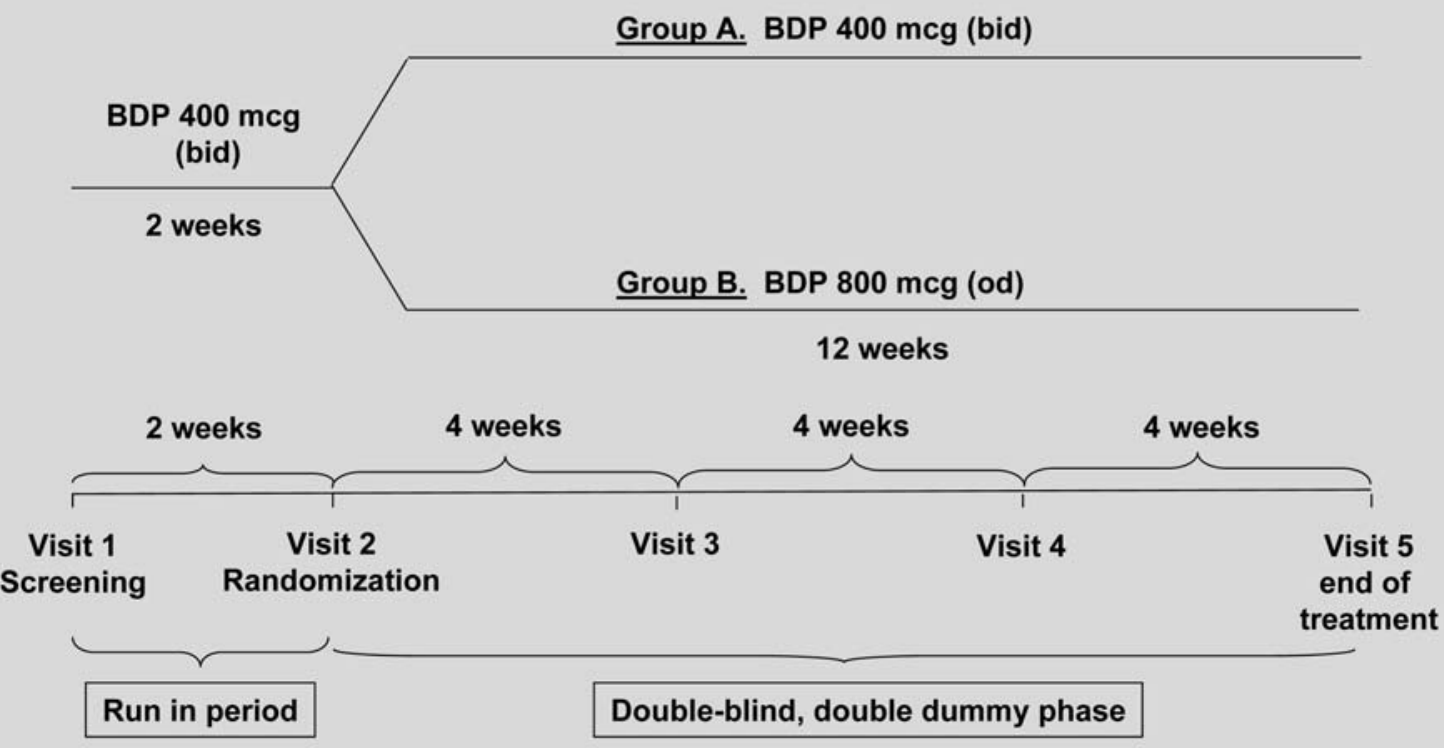

Fig. 2. - Study design. Children, eligible at the screening visit, entered a two-week run-in period, during which they were treated with BDP suspension (Clenil per aerosol, Chiesi, Italy), $800 \mathrm{mcg} /$ day administered b.i.d., through a nebuliser. At the end of the run-in period, patients entered a randomised, double-blind, two-armed parallel group study, consisting in a twelve weeks period. Children belonging to o.d. group were treated with placebo, matching BDP $400 \mathrm{mcg}$ in the morning, and BDP $800 \mathrm{mcg}$ in the evening, while children in b.i.d. group were treated with BDP suspension $400 \mathrm{mcg}$, in the morning and in the evening. 
the previous visit as reported on the patient's diary card.

The evaluation was done by selecting the appropriate number on an 8-point, 4 items scale (1-2 poor, 3-4 fair, 5-6 good, 7-8 total control). Compliance to study drugs was assessed by counting the vials returned at each visit (all containers and unused study drug) and by reviewing the diary card records.

\section{Tolerability Evaluations}

The tolerability was evaluated by adverse event reporting at each clinic visit, physical examinations, vital signs, and laboratory tests. A complete physical examination, in which height, weight, sitting blood pressure, and pulse rate were measured, was ducted at each visit. Cortisol and creatinine urinalysis was performed at visit 2 and was repeated at visit 5 (week 12 after randomisation). Urine samples were collected in the morning of the visit.

\section{Statistical analyses}

All the analyses were carried out on all randomised patients, according to the Full Analysis Set (FAS) approach. Descriptive statistics were provided for the analysis of all demographic variables, clinical characteristics and efficacy variables. Continuous variables were expressed as mean value, standard errors, while for categorical variables, frequency distributions were performed. Major respiratory parameters (PEF absolute and \% of predicted, $\mathrm{FEV}_{1}$ absolute and \% of predicted, FVC) were first of all analysed by descriptive statistics by visit and also by absolute difference between each study period time point and the baseline value. In addition, the variation of these parameters on all the visits were evaluated by means of repeated-measures analysis (Anova with Proc MIXED) in order to observe the effect of study drugs in intermediate visits. Statistical significance was met if the $P$ value $<0.05$. The statistical analysis was performed using STAT module of the SAS System version 9.1 for Windows.

\section{Results}

A total of 74 patients were screened between January 2003 and June 2004 at the eight institutions participating in the study, of which nine did not complete the run-in phase and did not enter the double blind period (six for consent withdrawal, one for occurrence of acute upper respiratory tract infection, two lost to follow-up).

The 65 remaining patients were randomly assigned to BDP $800 \mathrm{mcg}$ o.d. and to BDP $400 \mathrm{mcg}$ b.i.d. Patient demographics and baseline characteristics are shown in table 1 , groups were well matched and no significant difference was shown except for a higher prevalence of male children in the o.d. group. 43 patients completed the twelveweek study period with no significant difference between groups in discontinuation rates. Reasons for discontinuation included lost to follow-up (eight patients), consent withdrawn (ive patients), adverse event/intercurrent illness (four patients) (see below), and other reasons (five patients). Overall 63 patients, 30 in the BDP o.d. and 33 in the BDP b.i.d. group were evaluable for efficacy and entered the Full Analysis Set (FAS).

\section{Pulmonary function and home PEF monitoring}

In the two-week run-in period, treatment with BDP $800 \mathrm{mcg} /$ day b.i.d. was effective in improving pulmonary function. Indeed, comparison of values collected at the screening visit and at the end of runin period, showed a significant increase in $\mathrm{FEV}_{1}$ and $\mathrm{FVC}$, both evaluating the children as a whole group or as b.i.d. and o.d. groups (fig. 3A and 3B). The improvement in pulmonary function parameters was maintained in both treatment groups throughout the duration of the study period without significant difference between visit 2 (randomization) and visit 5 (end of treatment) or between the two treatment groups.

Morning PEF showed a progressive significant increase at each control visit; the mean change from run-in at the end of treatment (weeks 9/12) was $54.32 \pm 15.52 \mathrm{~L} / \mathrm{min}(\mathrm{p}=0.002)$ in the BDP o.d. group and $20.83 \pm 8.41 \mathrm{~L} / \mathrm{min}(\mathrm{p}=0.02)$ in the b.i.d. group (fig. 4A). The mean difference between groups in change from baseline at the end of study was $33.49 \mathrm{~L} / \mathrm{min}$ [ $95 \%$ confidence interval $(95 \%$ CI) $-0.91+67.90)$

Evening PEF showed a progressive increase at each control visit that was significant only in the $\mathrm{BDP}$ o.d. group; the mean change from run-in at the end of treatment was $50.30 \pm 16.21 \mathrm{~L} / \mathrm{min}$ $(p=0.005)$ in the BDP o.d. group and $14.61 \pm 8.90$ $\mathrm{L} / \mathrm{min}(\mathrm{p}=\mathrm{ns})$ in the b.i.d. group (fig. $4 \mathrm{~B})$. The mean difference between groups in change from baseline at the end of study was $35.68 \mathrm{~L} / \mathrm{min}(95 \%$ CI $-0.38+71.75)$.

A reduction in PEF diurnal variability was observed at the end of the run-in period in the two

Table 1. - Baseline characteristics of the study populations, mean values (SD)

\begin{tabular}{lcccccccc}
\hline group & $\mathbf{n}$ & Age & Sex & FEV $_{\mathbf{1}} \mathbf{L}$ & FEV $_{\mathbf{1}} \%$ & PEF L/s & PEF \% & FVC L \\
\hline BDP o.d. & 30 & $8.5(2.1)$ & $25 \mathrm{M} / 5 \mathrm{~F}$ & $1.61(0.49)$ & $82.13(7.71)$ & $3.25(0.92)$ & $84.88(22.66)$ & $1.91(0.68)$ \\
BDP b.id. & 33 & $8.8(2.3)$ & $17 \mathrm{M} / 16 \mathrm{~F}$ & $1.59(0.42)$ & $80.06(8.49)$ & $3.20(0.93)$ & $80.57(18.56)$ & $1.87(0.58)$ \\
\hline
\end{tabular}

$\mathrm{BDP}=$ beclomethasone dipropionate 
A.
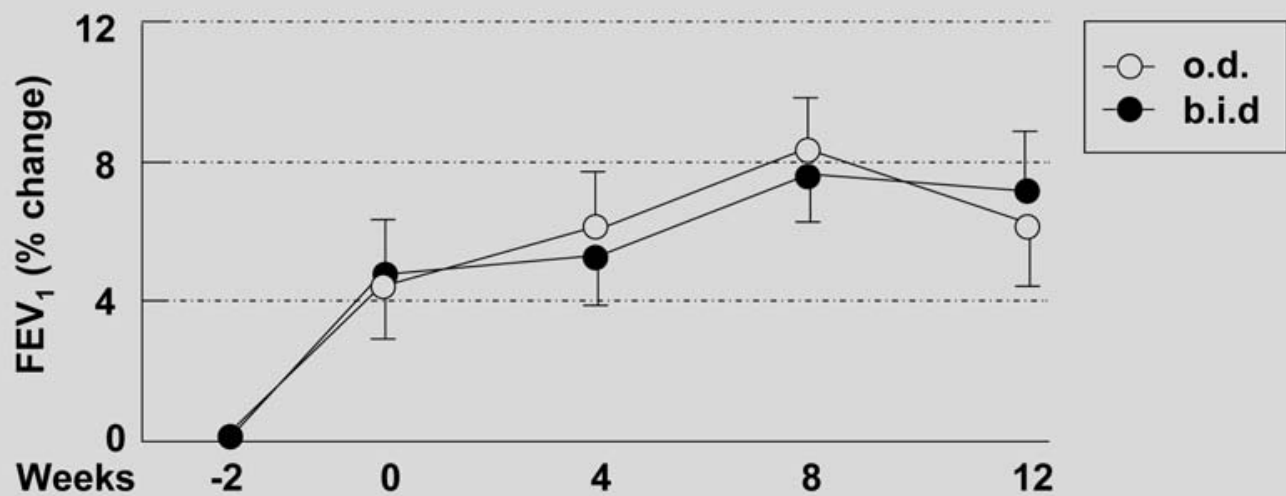

12

B.

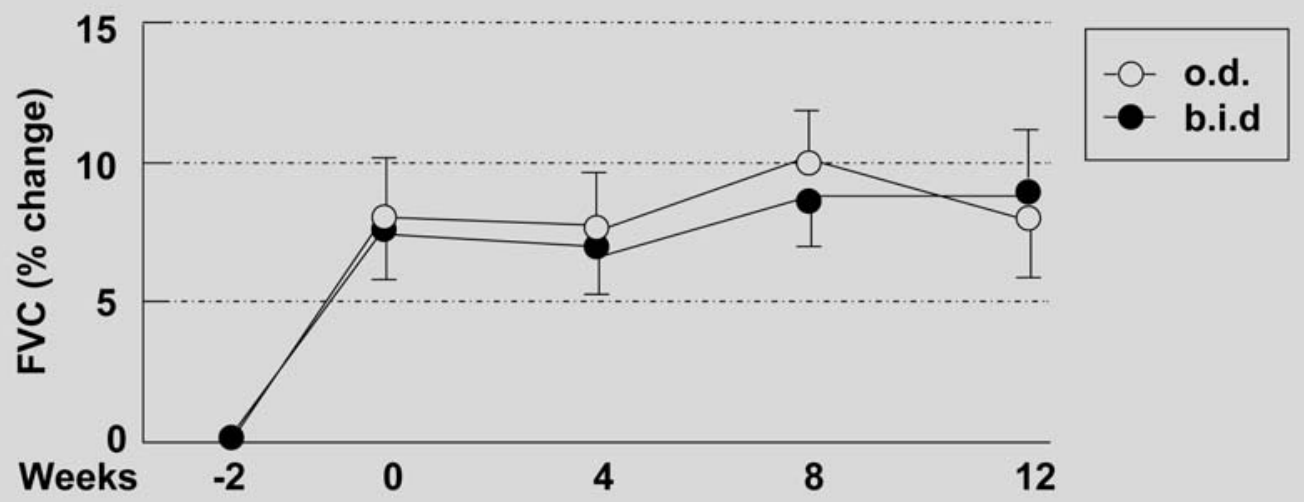

Fig. 3. - Pulmonary function of the two study groups BDP o.d. (open circles) and BDP b.i.d. (closed circles): A.) mean change in FEV $\%_{1}$ of predicted during the study period; B.) mean change in FVC \% predicted during the study period. Data is presented as least square means \pm standard errors.

treatment groups, maintained during the treatment period. Indeed, during the 2-week run-in period, the diurnal variability of PEF was $3.90 \pm 1.01 \%$ and $3.81 \pm 1.10 \%$ in the BDP o.d. and BDP b.i.d. groups, respectively, while at the end of the treatment period the mean change from baseline was $2.81 \pm 1.39 \%$ and $-2.45 \pm 1.60 \%$ in the BDP o.d. and BDP b.i.d. groups, respectively (fig. 4C).

\section{Asthma symptoms, rescue medication use and exacerbations}

A progressive increase in symptom-free days and nights was observed at the end of the run-in period in both treatment groups, followed by a progressive improvement during all the study period (table 2).

Table 2. - Symptom-free days and nights, asthma control, use of rescue medication (\% of patients)

\begin{tabular}{|c|c|c|c|c|c|}
\hline \multirow{2}{*}{ Group } & \multirow{2}{*}{ Time } & \multicolumn{2}{|c|}{ Symptom free } & \multirow{2}{*}{ Good-total asthma control } & \multirow{2}{*}{ Rescue medication use } \\
\hline & & Days & Nights & & \\
\hline \multirow[t]{5}{*}{ BDP o.d. } & Visit 1 & - & - & - & $100 \%$ \\
\hline & Visit 2 & $30 \%$ & $60 \%$ & $83 \%$ & $37 \%$ \\
\hline & Visit 3 & $42 \%$ & $78 \%$ & $80 \%$ & $40 \%$ \\
\hline & Visit 4 & $40 \%$ & $79 \%$ & $85 \%$ & $40 \%$ \\
\hline & Visit 5 & $80 \%$ & $92 \%$ & $95 \%$ & $35 \%$ \\
\hline \multirow[t]{5}{*}{ BDP b.id. } & Visit 1 & - & - & - & $100 \%$ \\
\hline & Visit 2 & $40 \%$ & $68 \%$ & $82 \%$ & $28 \%$ \\
\hline & Visit 3 & $60 \%$ & $90 \%$ & $85 \%$ & $20 \%$ \\
\hline & Visit 4 & $65 \%$ & $85 \%$ & $97 \%$ & $29 \%$ \\
\hline & Visit 5 & $76 \%$ & $87 \%$ & $96 \%$ & $29 \%$ \\
\hline
\end{tabular}

$\mathrm{BDP}=$ beclomethasone dipropionate. 
A.

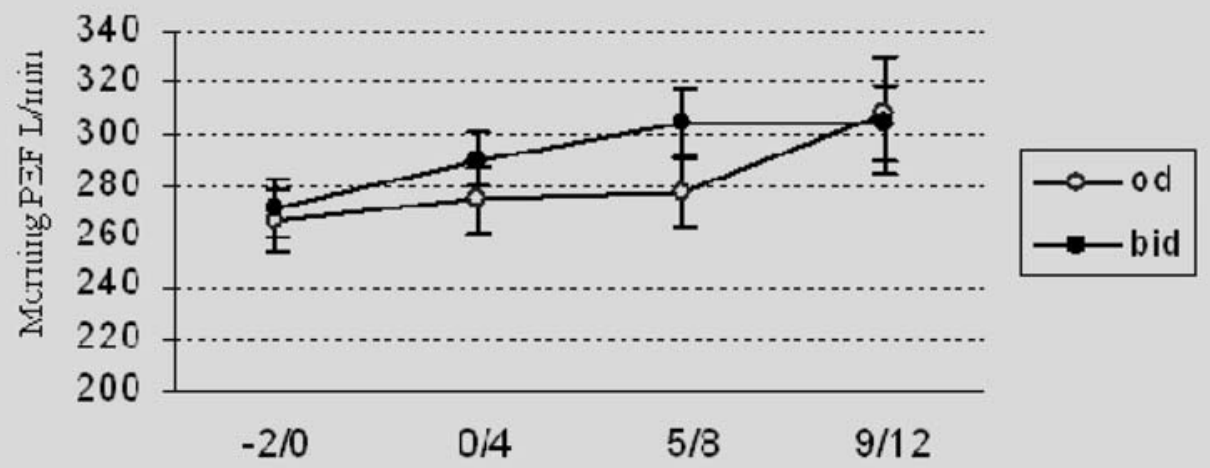

B.

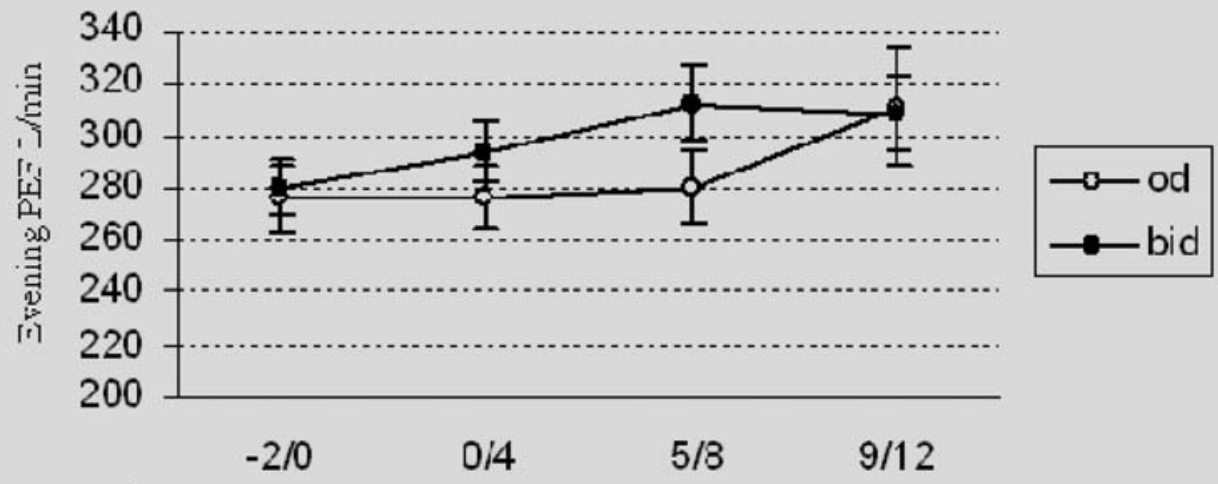

C.

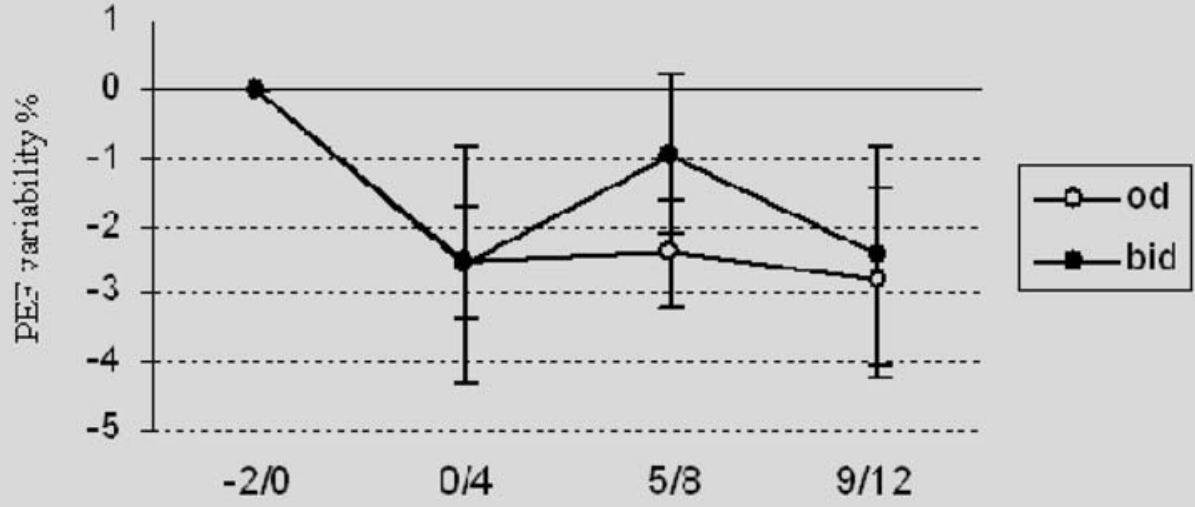

Fig. 4. - PEF values in the two study groups BDP o.d (open circles) and BDP b.i.d. (closed circles), recorded in diary cards during the run-in period (week -2/0) and during the trial (week 1/4, 5/8 and 9/12): A.) Morning PEF; B.) Evening PEF; C.) PEF change \% in diurnal variability calculated from morning and evening PEF. Data are presented as least square means \pm standard errors.

This improvement in symptom-free days and nights was associated with a "through-the-study" progressive increase in the percentage of children achieving asthma symptoms control as assessed by investigators during the scheduled visits (table 2).

Finally, while all patients were using rescue medication more than once a week before enrolment, two thirds of patients were free from rescue medication use at end of the twelve-week treatment period, with no significant differences were between treatment groups (table 2). No difference was found in the incidence of exacerbations during treatment period. Asthma exacerbations occurred in eight patients in the BDP o.d. group and seven patients in the BDP b.i.d. group (not shown).

\section{Tolerability}

The tolerability analysis was performed on all, randomised patients (65 valuable). No significant difference between groups was observed for adverse events frequency. The majority of the adverse events were of mild or moderate intensity and unrelated to the study medication and due to intercurrent diseases, except one patient who complained of persistent cough of mild intensity, assessed as possibly related to the drug administration. Eleven patients, seven in the BDP o.d. group and four in the BDP b.i.d. group, had to discontinue the study drug due to the occurrence of adverse events (mainly asthma exacerbation and intercurrent infections).

No differences were observed between the two study groups for the other tolerability variables, including vital signs, and physical examination. Although the study was not specifically designed to actively evaluate the presence of oral candidiasis, no spontaneous reporting of this adverse event was reported during the study period. Finally, no significant difference in urinary cortisol/creatinine ra- 
tio was detected between baseline values (40.04 \pm 4.65 and 46.39 \pm 9.03 , respectively in the o.d. and b.i.d. groups) and final values at the end of the twelve-week period $(47.30 \pm 8.33$ and $46.86 \pm 8.55$, respectively in the o.d. and b.i.d. groups) (fig. 5).

\section{Discussion}

The present study demonstrates in school-aged asthmatic children the efficacy and safety of BDP inhalation suspension dispensed via a jet nebulizer, at doses of $800 \mathrm{mcg}$ daily, and administered o.d. or b.i.d. Indeed, in the two weeks run-in period, a significant improvement in all pulmonary function values, rescue $\beta_{2}$-agonist use and clinical scores was observed. The improvement in $\mathrm{FEV}_{1}, \mathrm{FVC}$ and morning or evening PEF was then equally sustained in the o.d. group and in the b.i.d. group during the following twelve-week study period. In addition, a similar progressive increase in symptom free nights and days was detected in both treatment groups. Finally, no significant changes in urinary cortisol/creatinine ratio were detected between baseline and final value, with no differences between the two treatment groups.

The ultimate goal of asthma therapy is to achieve and maintain long-term control of asthma symptoms, to prevent exacerbations, and to attain the best possible lung function to enable patients to have normal life with no side effects from their medication [1]. It is now recognised that inflammation is a critical feature in the pathogenesis of asthma, and long-term therapy is therefore based primarily on ICS, the most effective drugs available for suppressing airway inflammation [1, 2].
Poor patient compliance, a major barrier to treatment and a major reason for treatment failure in asthma, may be improved prescribing drugs with high safety profile, providing easy and convenient to use devices, simplifying dosing regimens (e.g. once-daily administration), and educating the patient and the caregivers [19, 25].

BDP is a synthetic chlorinated corticosteroid diester, widely used by inhalation in the treatment of asthma, whose efficacy and safety have been proven by a variety of clinical studies [26, 27]. BDP is actually a poorly active pro-drug, which is rapidly hydrolysed by lung tissue lysosomal enzymes to a much more potent glucocorticoid, namely 17-beclomethasone monopropionate (17BMP) $[28,29]$. The relative binding affinity of 17BMP for the glucocorticoid receptor of human lung is approximately 30 times greater than that of the parent drug BDP and its stability in human lung is high, since only approximately $10 \%$ of $17-\mathrm{BMP}$ is hydrolyzed to beclomethasone $(\mathrm{BOH})$ within two hours [28, 29]. Some 17-BMP will avidly bind to corticosteroid receptors in the lung and be retained and some will be released and subsequently absorbed in the systemic circulation [28-30].

The high therapeutic index of inhaled BDP may result from a combination of high local potency in the lung and rapid metabolic inactivation of BDP and of its metabolites, especially 17-BMP, when they reach the systemic circulation [28-30]. This may explain the clinical results observed in the present study, also when BDP was administered o.d., and the high tolerability profile observed, with no modification of the urinary cortisol/creatinine ratio.

The rationale for administering the drug o.d. in the evening derives not only from clinical trials but

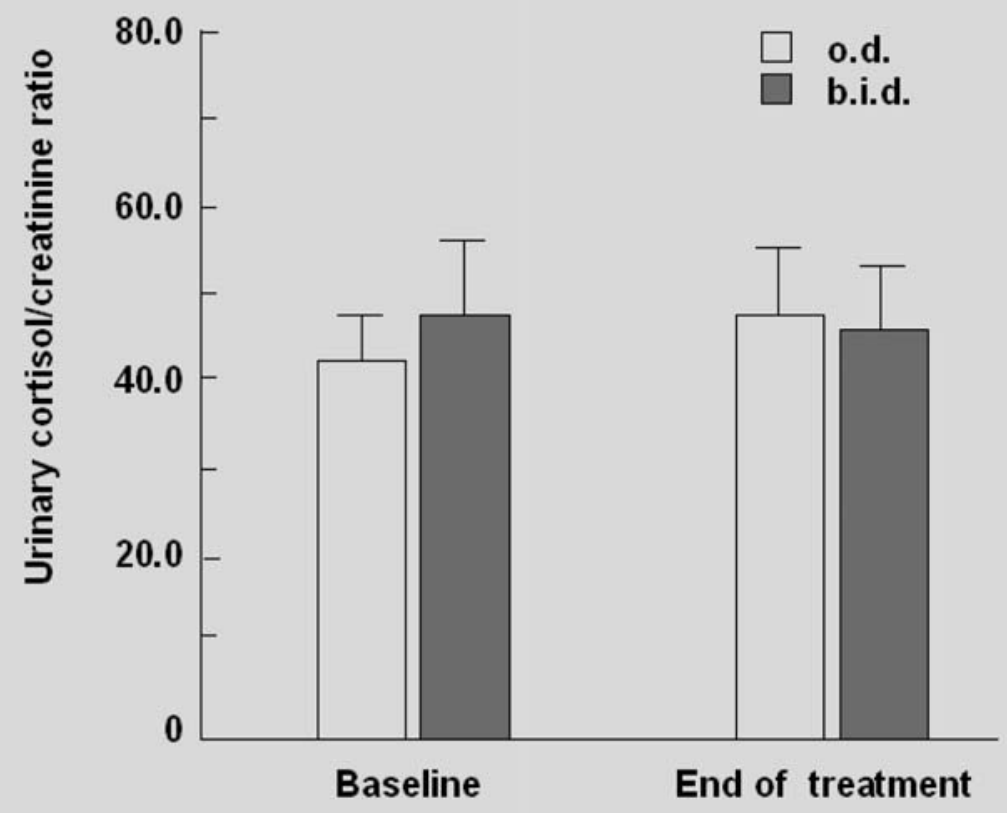

Fig. 5. - Urinary cortisol/creatinine ratio calculated from samples collected at visit 2 after the two-week run-in period (baseline) and at visit 5 at the end of the twelve weeks study period. Data is presented as least square means \pm standard errors. 
also from chronopharmacologic studies that have shown that the time of administration influences the efficacy and safety of inhaled and oral corticosteroids [31-33]. Asthma symptoms and airway inflammation may increase at night, so that late afternoon or evening administration of anti-asthmatic drugs may therefore optimise their effect.

Optimising drug delivery in the management of asthma involves consideration of the age of the patient, and selection of a device that reproducibly delivers an adequate dosage of the drug to the intrapulmonary airways and is suited to the patient's needs and abilities $[1,2,25]$. Many paediatric patients, particularly infants and young children, but also school-age children, are unable to use pMDIs and inhalation-driven DPIs effectively, either because they do not have sufficient coordination or inspiratory flow or are unable to perform the controlled inhalation technique [25]. Young patients often experience delivery and technique problems with inhaled therapy, resulting in under-utilisation of ICS, even when parents take responsibility for administering the medication [25].

Nebulisers, which are easy to use and do not require coordination, have been considered for years not convenient for the medium-long term treatment of airway diseases, because they are relatively inefficient in the generation of fine particles, that can reach the lower respiratory tract and their use is time consuming (for the longer administration times) [20]. New generation nebulisers, such as the one used in the present study, provided with breath enhanced bulb, are able to deliver a significant proportion of particles in sizes suitable to efficiently reach the lower airways with little variability $[20$, 22]. The "once-daily" nebulisation of the drug, makes the "longer administration times" a minor, acceptable weakness, in agreement with previous studies demonstrating that, in addition to behavioural or educational strategies, a simplification of dosing schedules, as reducing the number of doses per day and improving the ease of administration, may lead to increased patient compliance and, therefore, better asthma control [4, 5, 31, 32].

For these reasons there is increasing interest and evidence that supports once daily administration of corticosteroids in asthma so that the most recent guidelines suggest for persistent asthma in adults and children older than five years a regular treatment with low dose ICS administered once or twice daily [1].

In conclusion, we have reported for the first time preliminary data suggesting that mediumterm treatment with a daily dose of $800 \mathrm{mcg}$ of nebulised BDP, administered o.d. is similarly effective as the same dose administered b.i.d., the two treatment schedule providing similar efficacy in maintaining pulmonary function and improving symptoms of asthmatic children whose asthma had been previously controlled with a short course of nebulised BDP, administered b.i.d. Efficacy was associated with a good tolerability profile that did not change when the daily dose was administered in a single dose. These preliminary results need to be confirmed in a larger patient population.

\section{References}

1. Global Strategy for Asthma Management and Prevention. NIH Publication No 02-3659 Issued January, 1995 (updated 2005).

2. National Asthma Education Prevention Program (NAEPP). Expert panel report: guidelines for the diagnosis and management of asthma-update on selected topics. J Allergy Clin Immunol 2002; 110: 141-219.

3. Bender B, Milgrom H, Rand C, Ackerson L. Psychological factors associated with medication nonadherence in asthmatic children. J Asthma 1998; 35: 34753.

4. Guest JF, Davie AM, Ruiz FJ, Greener MJ. Switching asthma patients to a once-daily inhaled steroid improves compliance and reduces healthcare costs. Prim Care Respir J 2005; 14: 88-98.

5. Mann M, Eliasson O, Patel K, ZuWallack RL. A comparison of the effects of bid and qid dosing on compliance with inhaled flunisolide. Chest 1992; 101: 496-9.

6. Hyland ME. Rationale for Once-Daily Therapy in Asthma Compliance Issues. Drugs 1999; 58 (Suppl. 4): 1-6.

7. Simons FE. Benefits and risks of inhaled glucocorticoids in children with persistent asthma. J Allergy Clin Immunol 1998; 102: S77-84.

8. Dubus J-C, Anhoj J. A review of once-daily delivery of anti-asthmatic drugs in children. Pediatr Allergy Immunol 2003; 14: 4-9.

9. Jonasson G, Carlsen KH, Blomqvist P. Clinical efficacy of low-dose inhaled budesonide once or twice daily in children with mild asthma not previously treated with steroids. Eur Respir J 1998; 12: 1099-104.

10. Shapiro GG, Mendelson LM, Pearlman DS. Once-daily budesonide inhalation powder (Pulmicort Turbuhaler) maintains pulmonary function and symptoms of asthmatic children previously receiving inhaled corticosteroids. Ann Allergy Asthma Immunol 2001; 86: 63340.

11. Moller C, Stromberg L, Oldaeus G, Arwestrom E, Kjellman M. Efficacy of once daily administration of budesonide by Turbuhaler in children with stable asthma. Pediatr Pulmonol 1999; 28: 337-43.

12. Mellon M, Leflein J, Walton-Bowen K, Cruz-Rivera M, Fitzpatrick S, Smith JA. Comparable efficacy of administration with face mask, or mouthpiece of nebulized budesonide inhalation suspension for infants and young children with persistent asthma. Am J Respir Crit Care Med 2000; 162: 593-8.

13. Miller-Larsson A, Mattsson H, Hjertberg E, et al. Reversible fatty acid conjugation of budesonide.Novel mechanism for prolonged retention of topically applied steroid in airway tissue. Drug Metab Depos 1998; 26 : 623-30.

14. Sabatini F, Silvestri M, Scarso L, Brazzola G, Rossi GA. The antiinflammatory activity of budesonide on activated human airway epithelial cells is lasting after removal of the drug from cultures. J Asthma 2002; 39: 11-20.

15. Gagnon M, Cote J, Milot J, Turcott H, Boulet LP. Comparative safety and efficacy of single or twice daily administration of inhaled beclomethasone in moderate asthma. Chest 1994; 105: 1732-7.

16. McGivern DV, Ward M, Macfarlane JT, Roderick Smith WH. Failure of once daily inhaled corticosteroid treatment to control chronic asthma. Thorax 1984; 39: 933-4.

17. Munch EP, Laursen LC, Dirksen A, Weeke ER, Weeke B. Dose frequency in the treatment of asthmatics with inhaled topical steroids. Comparison between a twice daily and a once daily dosing regimen. Eur J Respir Dis 1985; 67: 254-60. 
18. Edsbäcker S. Pharmacological factors that influence the choice of inhaled corticosteroids. Drugs 1999; 58 Suppl. 4: 7-16.

19. O'Connell EJ. Optimizing inhaled corticosteroid therapy in children with chronic asthma. Pediatr Pulmonol 2005; 39: 74-83.

20. Brownlee KG. A rationale for the use of nebulized steroids in children. Eur Respir Rev 1997; 7: 177-9.

21. Dolovich MB, Ahrens RC, Hess DR, et al. Device selection and outcomes of aerosol therapy: Evidencebased guidelines: American College of Chest Physicians/American College of Asthma, Allergy, and Immunology. Chest 2005; 127: 335-71.

22. American Thoracic Society. Standards for the diagnosis and care of patients with chronic obstructive pulmonary disease (COPD) and asthma. Am Rev Respir Dis 1987; 136: $225-244$.

23. Terzano C, Cremonesi G, Panza I. Particle size and gravimetric characteristics of Clenny Aerosol, a new jet nebulizer with breath enhanced bulb. Eur Respir $J$ 2001: 18; 99s.

24. Banov CH, Howland WC III, Lumry WR. Once-daily budesonide via Turbuhaler improves symptoms in adults with persistent asthma. Ann Allergy Asthma Immunol 2001; 86: 627-632.

25. American Thoracic Society. Standardization of spirometry, 1994 update. Am J Respir Crit Care Med 1995; 152: $1107-36$
26. Szefler SJ. Current concepts in asthma treatment in children. Curr Opin Pediatr 2004; 16: 299-304.

27. Adams N, Bestall J, Jones P. Inhaled beclomethasone at different doses for long-term asthma. Cochrane Database Syst Rev 2001; (1): CD002879.

28. Foe K, Brown KF, Seale JP Comparative kinetics of metabolism of beclomethasone propionate esters in human lung homogenates and plasma. J Pharm Sci 2000; 89: 1143-1150.

29. Wurthwein G, Rohdewald P. Activation of beclomethasone dipropionate by hydrolysis to beclomethasone-17monopropionate. Biopharm Drug Dispos 1990; 11: 381-94.

30. Agertoft L, Laulund LW, Harrison LI and Pedersen S. Influence of particle size on lung deposition and pharmacokinetics of beclomethasone dipropionate in children. Pediatr Pulmonol 2003; 35: 192-199.

31. Campbell LM. Once-daily inhaled corticosteroids in mild to moderate asthma: improving acceptance of treatment. Drugs 1999; 58 (Suppl. 4): 25-33.

32. Diane J. Pincus, Stanley J. Szefler, Lynn M. Ackerson, Richard J. Martin. Chronotherapy of asthma with inhaled steroids: The effect of dosage timing on drug efficacy. J Allergy Clin Immunol 1995; 95: 1172-8.

33. Diane J. Pincus, Teresa R. Humeston, Richard J. Martin. Further studies on the chronotherapy of asthma with inhaled steroids: The effect of dosage timing on drug efficacy. J Allergy Clin Immunol 1997; 100: 771-4.

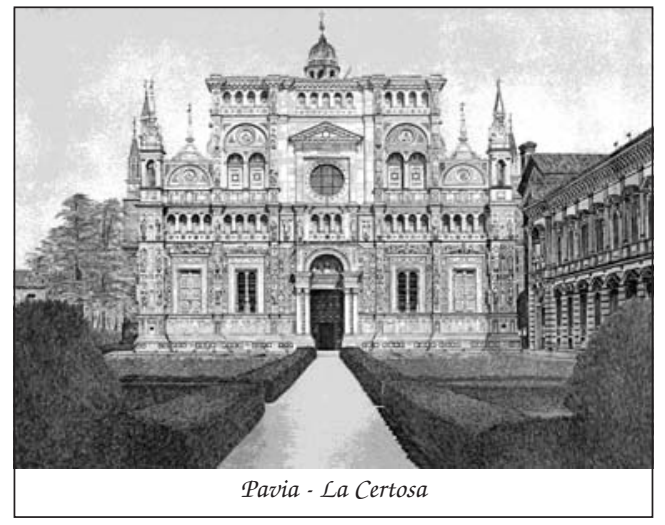

